\title{
Simulating drone and bodily gestures: a behavioral study
}

\author{
Anna Kolesnikov', Martina Montalti², Marta Calbi², Nunzio Langiulli², Michele \\ Guerra $^{1}$, Vittorio Gallese ${ }^{2,3}$, Maria Alessandra Umiltà ${ }^{3,4}$ \\ ${ }^{1}$ Department of Humanities, Social Sciences, and Cultural Industries, University of Parma, Parma, Italy \\ ${ }^{2}$ Department of Medicine and Surgery, Unit of Neuroscience, University of Parma, Parma, Italy \\ ${ }^{3}$ Department of Art History and Archeology, Columbia University, New York, USA \\ ${ }^{4}$ Department of Food and Drug, University of Parma, Parma, Italy
}

Version: $28-06-2021$

*Correspondence:

Anna Kolesnikov

anna.kolesnikov@unipr.it

Keywords: embodied simulation, ascent, gesture, drones, naturalistic video stimuli 


\section{Introduction}

The discovery of mirror neurons (Di Pellegrino et al. 1992; Rizzolatti et al. 1996; Gallese et al., 1996) enabled the identification of a neural mechanism mapping the direct connection between the visual description of a motor act and its execution (Gallese et al. 1996). According to embodied simulation theory, humans tacitly 'simulate' the actions of the other by mapping them in the sensorimotor cortex of the brain (Gallese 2005; Gallese and Sinigaglia 2011; Gallese 2014). Indeed, a growing body of evidence corroborates the existence of a link between action execution and perception in humans (see: Gallese 2009). The present study investigates the relationship between drone and human movement, perceived motion and involvement measures, specifically testing the predictions of the framework of embodied cinema (Coëgnarts and Kravana 2015; Gallese and Guerra 2020) using a custom-made, naturalistic set of stimuli.

\section{The mirror mechanism and mediated actions}

It has been shown that numerous human cortical areas, such as the ventral part of the pre-central gyrus, the posterior part of the inferior frontal gyrus and the rostral part of the inferior parietal lobule are activated both during the execution and the observation of goal-orientated actions (see Frith and Frith 2010; Hari and Kujala 2009; Gallese, Keysers and Rizzolatti 2004), such as videos of hand, mouth and foot actions (Buccino et al. 2001; Aziz-Zadeh et al. 2006). Electroencephalography (EEG) studies have demonstrated a sensorimotor alpha Event-Related Desynchronization (ERD, a marker for sensorimotor resonance) during the observation of different types of grasping (Muthukumaraswamy, Johnson and McNair 2004), aimless movements (Babiloni et al. 2002) and videos of communicative hand gestures and grasping within social contexts (Streltsova et al. 2010). It has also been demonstrated that the observer's motor repertoire or familiarity modulate motor cortical activity. In particular, Calvo-Merino et al. (2005, 2006) and Orgs et al. (2008) demonstrated that expert dancers observing videos of dancing steps in their particular professional style have stronger activation of motor areas with respect to when they observe dancing steps in which they do not have prior professional experience. A similar result was echoed in studies by Aglioti et al. (2008) and Abreu et al. (2012) on motor activity during the observation of videos of basketball sequences by expert basketball players vs. non-athletes. This body of research supports the claim that the link between action execution and perception constitutes the basis of social cognition, as concretized by embodied simulation theory, and the reported context sensitivity of 
visuomotor/sensorimotor activation supports the claim that these motor simulation processes are fine-tuned to serve specific social interactions.

\section{Film and sensorimotor engagement}

The role of sensorimotor and visceromotor mechanisms in shaping film experience has been of interest to empiricists since the advent of cinema. In his recordings of the desynchronization of EEG rhythms in the alpha band $(8-13 \mathrm{~Hz})$ from multiple electrodes, the neurologist Henri Gastaut and his collaborators were the first to demonstrate that motor cortex activation occurs not only during action execution but also during the observation of actions; namely, the film footage of a boxer (Gastaut and Bert 1954). Empirical evidence for a direct link between perception and action are informing a contemporary, interdisciplinary reassessment of how the brain-body system is engaged during film experience (Carluccio and Villa 2006; D'Aloia and Eugeni 2014; Coëgnarts and Kravanja 2015; Carocci 2018; Eugeni 2018; Gallese and Guerra 2012, see also 2020). According to the framework of embodied cinema, the meaning-making process in film is considered to be inextricably linked to the interrelation between the brain, body and environment of the viewer (Gallese and Guerra 2012/2020). According to Gallese and Guerra, embodied simulation theory can enrich film studies at the receptive and creative levels, shedding new light on at least three types of "film embodiment": 1) acting style, 2) film style, and 3) and the spectator's responses to filmed bodies and objects (Gallese and Guerra, 2012). The first stage of embodiment, i.e., acting, which brings the audience into the forefront of "action" and "tactility", and film style (e.g., the camera), emerges as a "negotiation" with the acting body. The role of the camera is integral, endowing the cinematic experience with kinesthetic and tactile cues that animate the film with "vitalizing" qualities and a subjectivity of its own (Gallese and Guerra 2014). Heimann and colleagues (2014) investigated the effect of camera movement on motor cortex activation in viewers, showing that the Steadicam elicits a stronger motor resonance compared to a "zoom". This is explained by the greater sense of "being there" that the Steadicam affords, in this way facilitating the motor simulation of actions executed in the scene. The stronger motor resonance measured in the Steadicam condition may also be driven by motor engagement with the "trace" of the Steadicam's own movement across the scenic space. Replicating the study in an empty room, Heimann et al. (2019) found that greater motor resonance was again evoked for the Steadicam, providing the first empirical evidence that camera movement alone can modulate spectator's bodily engagement during film experience. Although there is a growing number of theoretical (Virilio 1994; Verhoeff 2012; 
Campbell 2018; Agostinho, Maurer and Veel 2020; Christiansen 2020; Jablonowski 2020) and technological (Eriksson et al. 2019; Cherpillod, Mintchev, and Floreano 2019) studies on the sensorimotor capacities of drone flight and drone vision, to date no studies have investigated the effect of drone footage with and without human bodily movement on spectators' cognitive behavioral mechanisms.

\section{Research aims}

As described in the aforementioned literature, there are numerous studies on sensorimotor engagement during audiovisual experience, in support of embodied simulation theory. Little research has been done on how slowing the speed at which this movement is projected impacts participants' perception bodily involvement with the scene (Sobchak 2006; Rogers 2013). Thus, the aims of the present study are to investigate the impact of drone and human movement on spectators' reception of appeal, involvement and perceived motion and time. Specifically, the impact of Drone Movement (Ascending, Descending, Still), Actor Presence (Female, Male, None [no actor]) and Image Speed (Normal, Slow, Very Slow) were investigated with respect to spectators' ratings of perceived Duration, perceived Movement, Liking, Physical and Emotional Involvement. In order to achieve these aims and in line with the growing trend of using naturalistic stimuli for cognitive science research on audiovisual media (Sonkusare, Breakspear and Guo, 2019), we created a novel, ecologically valid set of video stimuli filmed by means of a drone. We hypothesize that: 1) Female and Male Actor Presence will be perceived as evoking significantly greater Movement, Physical Involvement, Emotional Involvement and Liking with respect to None (i.e., No Actor Presence); 2) Ascending Drone Movement will be perceived as evoking greater Movement, Physical Involvement and Emotional Involvement than Descending and Still (due to greater perceived effort/exertion); and 3) Very Slow and Slow Image Speed will be perceived as evoking significantly longer Duration, and greater Liking, Movement, Emotional Involvement and Physical Involvement with respect to Normal (due to greater perceived effort/exertion).

\section{Materials and methods}

\section{Participants}

Participants were recruited through opportunity sampling using Facebook, which filtered individuals for age and residence in Parma. Interested participants were further screened using 
a survey, and individuals with professional filmmaking or film studies backgrounds were excluded from the study. In total, 31 healthy volunteers of Italian nationality took part in the experiment: 14 female and 17 males, mean age 25.03 (Standard Deviation $-S D=4.63$, $\min =$ 18 , $\max =35$ ). We calculated the sample size by using $\mathrm{G}^{*}$ Power 3.1 (Faul et al., 2007) and running a priori power analysis equivalent to that of a mixed-design multilevel linear model, with a level of power of 0.80 , assuming a Cohen's $F$ effect size equal to 0.25 (medium effect size), an alpha level of 0.05 , and 5 measurements. All participants provided written informed consent to participate in the study, which was conducted in accordance with the Declaration of Helsinki (2013), complying with the ethical standards of the Italian Board of Psychologists as well as the Ethical Code for Psychological Research of the Italian Psychological Society and the Ethical Committee of the Area Vasta Emilia Nord (AVEN).

\section{Stimuli}

The stimuli were modeled after the staircase scene from the soviet film The Cranes Are Flying (Mikhail Kalatozov, USSR, 1957) and filmed in collaboration with professional filmmaker Fabrizio La Palombara and professional drone pilot Sandro Russello (Fly to Discover). Specifically, the videos were filmed with a DJI Phantom 4 Pro Drone with a Sony Alpha 7s mounted on its platform. One female and one male actor were instructed to run up and down a staircase while the drone tracked their movements, ascending and descending vertically the stairwell (see Fig. 1). The drone also filmed ascending and descending variants without the presence of the actors. During filming, the drone maintained a constant distance from the actors (approximately 2 meters) while it rotated on its axis. For the control condition, both the actors and the drone remained still. Premiere Pro $\mathrm{CC}$ was used to edit the raw drone footage into experimental stimuli in MP4 format with AAC and H.264 codecs and 1920 x 1080 resolution. Each clip had a frame rate of 25 frames per second, with a total of 250 frames, or $10000 \mathrm{~ms}$ per clip. A cross dissolve of 25 frames $(1000 \mathrm{~ms})$ was included at the beginning and end of each clip in order to create a more fluid transition between the fixation cross and stimulus frames (see Fig. 2A-I). In order to control for possible confounding effects, clips were converted into monochrome. 

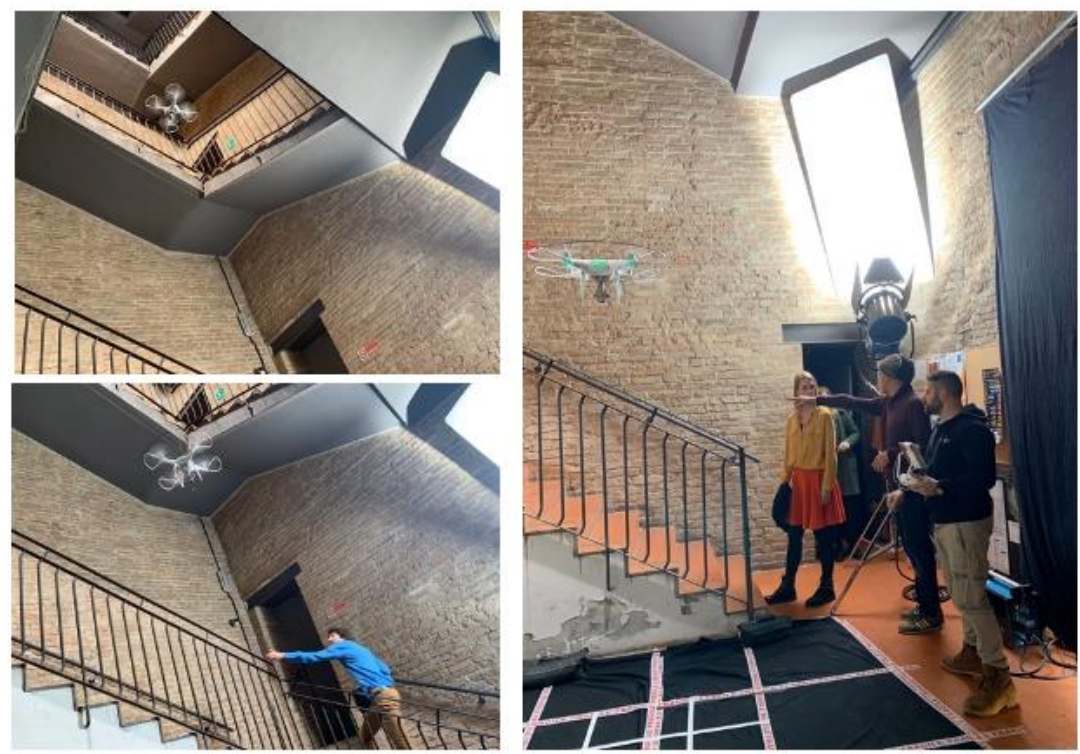

Fig. 1 | Production. Shooting the videos using a DJI Phantom 4 Pro Drone

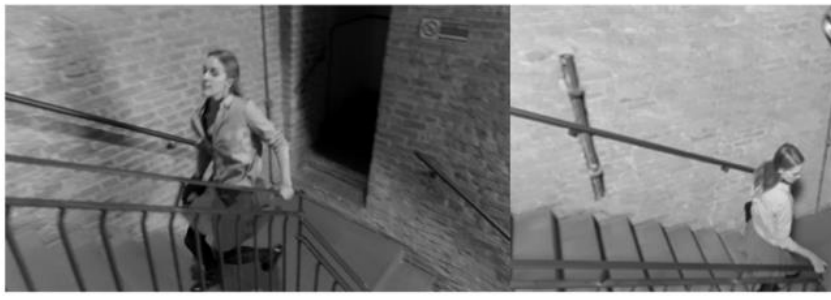

A

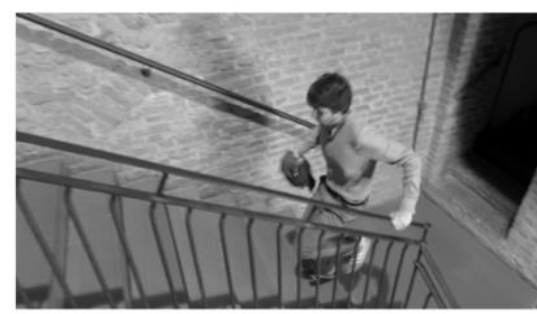

$\mathrm{D}$

$\mathrm{E}$
B

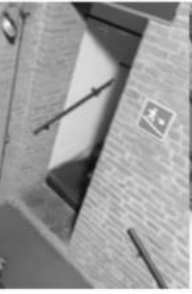

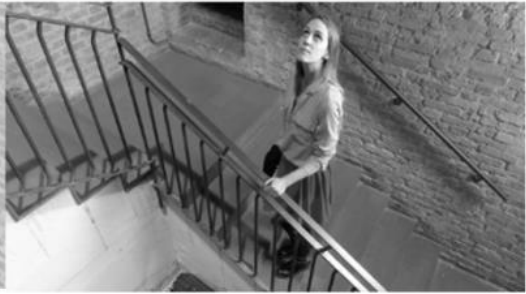

$\mathrm{C}$

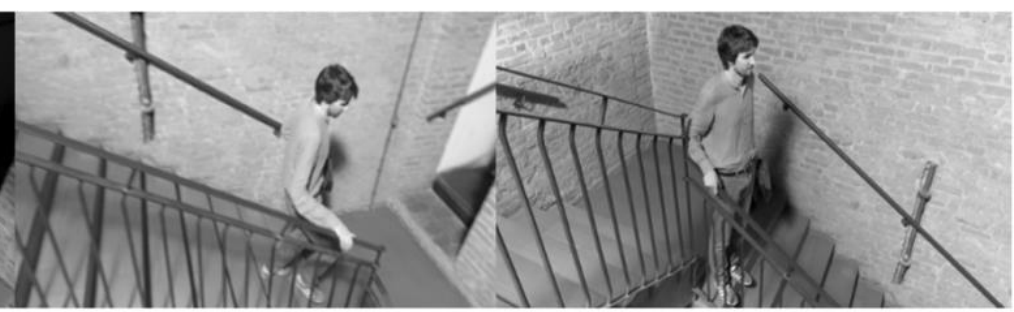

$\mathrm{F}$

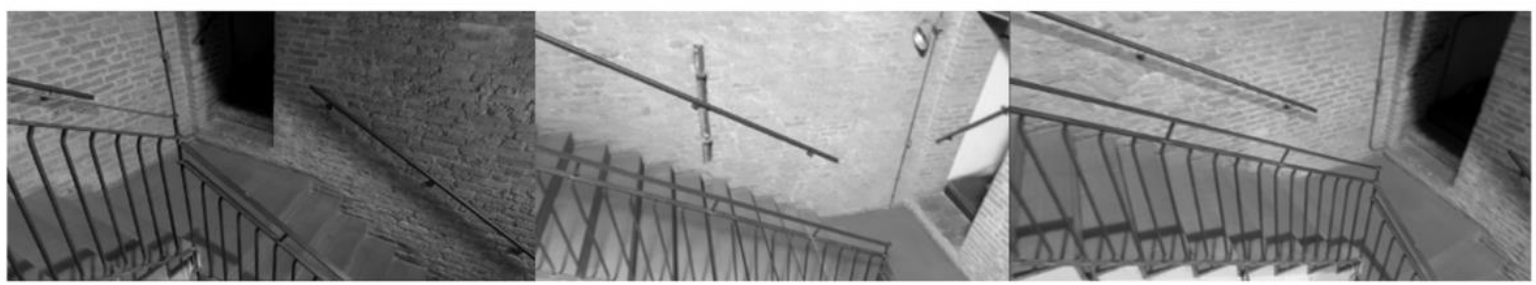

G

$\mathrm{H}$

I

Fig. 2A - I | Stimuli. Ascending conditions for Female, Male and None, respectively (A, D, G); Descending conditions for Female, Male and None, respectively (B, E, H); and Still conditions for Female, Male and None, respectively (C, F, I). 
In total, 81 video clips were created in the following modalities: Drone Movement (Ascending, Descending, Still), Actor Presence (Female, Male, None/No Actor) and Image Speed (Normal: 100\%, Slow: 75\%, Very Slow: 50\%). A total of 27 clips were made with normal (100\%) image speed ( 250 frames/clip), 27 clips were then slowed down to: $75 \%$ of the original image speed (333 frames/clip), and 27 clips were slowed down to 50\% of the original image speed (500 frames/clip). See Tab. 1.

\begin{tabular}{cccc}
\hline Stimulus & Drone Movement & Actor Presence & Image Speed \\
\hline $1-27$ & \multirow{2}{*}{ Ascending } & Female & N, S, VS \\
& & Male & N, S, VS \\
& None & N, S, VS \\
\hline $28-54$ & \multirow{2}{*}{ Descending } & Female & N, S, VS \\
& & Male & N, S, VS \\
& & None & N, S, VS \\
& & Female & N, S, VS \\
& \multirow{2}{*}{ Still } & Male & N, S, VS \\
& & None & N, S, VS
\end{tabular}

Tab. 1 | Stimuli /conditions. Total number of stimuli: 81. N: Normal, S: Slow, VS: Very Slow.

\section{Procedure}

Using a brief survey, participants with backgrounds in professional filmmaking or film studies were excluded. Upon arrival, participants were asked to make themselves comfortable and were given instructions about the study. The experimental session consisted of two different and randomized phases.

In the first phase, participants were asked to fill out a series of questionnaires. Empathy was assessed in all participants using the Interpersonal Reactivity Index (IRI Davis 1980). The subscales of interest are Empathic Concern (EC), which assesses "other-oriented" feelings of sympathy and concern for unfortunate others, and Fantasy (F), which taps respondents' tendencies to transpose themselves imaginatively into the feelings and actions of fictitious characters in books, movies, and plays. Both subscales consist of 7 self-report items. Motor imagination was assessed in all participants using the VMIQ-2 (Roberts et al. 2008). The VMIQ-2 consists of 36 self-report items that measure the vividness of motor imagination, with three subscales: External Visual Imagination (i.e., imagining yourself carry out the movement as you observe from the outside), Internal Visual Imagination (i.e., imagining yourself carry out the movement through your own eyes), and Kinesthetic Imagination (i.e., imagining the 
physical sensation of carrying out the movement). Immersive tendencies were assessed in all participants using the ITQ (Witmer and Singer 1996). The ITQ attempts to identify and measure possible individual differences in the abilities or tendencies of individuals to immerse themselves in different environmental situations. The questionnaire consists of 18 self-report items. The subscale of interest here is Involvement ( 5 items), which assesses the propensity to passively get involved in witnessing something, such as books, television and movies. Handedness was assessed in all participants using the Edinburgh Inventory (Oldfield 1971). Containing 19 self-report items, the survey assessed whether participants were right-handed, left-handed or ambidextrous. Left-handed subjects were excluded.

In the second phase, participants were asked to perform a computer task in which the 81 video stimuli were presented in randomized order. In each trial, a fixation cross was presented for $1000 \mathrm{~ms}$, a video stimulus was presented for $10000 \mathrm{~ms}$, and 5 questions were presented with no time limit (see Fig. 3). Each stimulus was presented once, each time followed by the following questions, also in randomized order: 1) "How long was the duration of the stimulus?"; 2) "How much movement did you perceive?"; 3) "How much rotation did you perceive?"; 4) "How physically involved did you feel?"; and 5) "How emotionally involved did you feel?". Participants were asked to observe the stimuli and answer the questions as quickly and as accurately as possible (no specific time limit was given), using the mouse to click on the Visual Analogue Scale (VAS) ranging from 0 (very little) to 100 (very much). Only for the "Duration" question, 0 signified "down" and 100 signified "up". The study design was the following: 3 Drone Movements (Ascending, Descending, Still) * 3 Actor Presences (Female, Male, None) * 3 Image Speeds (Normal, Slow, Very Slow), for a total of 27 conditions. Each experimental condition was repeated 3 times, for a total of 81 stimuli, with 5 questions repeated per stimulus, for a total of 405 presented trials. Before carrying out the experimental procedure participants were presented with a brief training phase to become accustomed with the task. After the experimental session participants were asked to fill out a short debriefing survey about their experience. The experimental session and was conducted in a quiet room, on a screen positioned approximately $60 \mathrm{~cm}$ from the participant. The experimental task was programmed using Psychopy 3.0 software (Peirce, 2019). 


\section{Analysis}

In order to investigate whether VAS ratings are modulated by Drone Movement, Actor Presence and Image Speed, a linear mixed effect analysis was carried out for each variable. Participants' ratings were entered as dependent variables (Emotional Involvement, Physical Involvement, Movement, Liking, and Duration), Drone Movement (3 levels: Ascending, Descending, Still), Actor Presence (3 levels: Female, Male, None) and Image Speed (3 levels: Normal, Slow, Very Slow) as independent fixed variables, and participant intercepts as random effects. Tukey's test was used for post-hoc comparisons among means, where an error probability of less than $5 \%(\mathrm{p}<.05)$ was considered significant in a population sample size of $\mathrm{N}=31$. All analyses were performed using R software (R Core Team 2019) and lme4 (Bates et al. 2015), ordinal (Christensen, 2019), effects (Fox, 2003) and emmeans (Lenth, 2020) functions; for data visualization, the ggplot2 package was used (Wickham 2016).

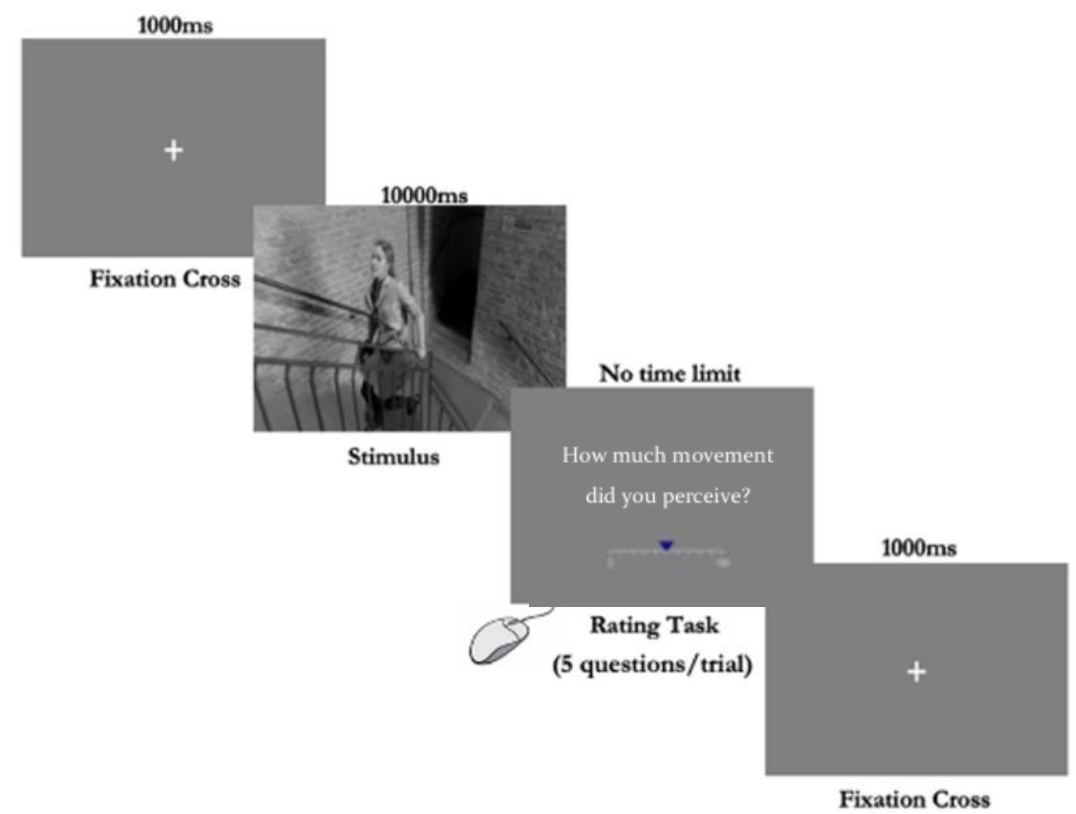

Fig. 3 | Example of experimental trial. Components: fixation cross frame (1000 ms), stimulus frame (10000 ms) and the Visual Analogue Scale (VAS) rating task (scale from 0 to 100, no time limit). Experiment was created using Psychopy 3.0.

\section{Results}

\section{Duration}

The model explained $72.02 \%$ of the variance in Duration ratings, taking into account the random effects $\left(R^{2}{ }_{m}=0.01, R^{2} c=0.72\right)$. The model revealed a significant main effect of Drone Movement $\left(\chi^{2}(2)=15.07, p<.001\right)$, showing that participants found Ascending to have a longer 
perceived Duration than Still $\left(t_{(780)}=2.95, \mathrm{SE}=0.95, p=.009\right.$; Ascending: $\mathrm{M}=42.2, \mathrm{SE}=$ 3.27; Still: $\mathrm{M}=39.4, \mathrm{SE}=3.27)$, and Descending more than Still $\left(t_{(780)}=3.66, \mathrm{SE}=0.95, p<\right.$ .001 ; Descending: $\mathrm{M}=42.9, \mathrm{SE}=3.27$ ), see Figure 4 .

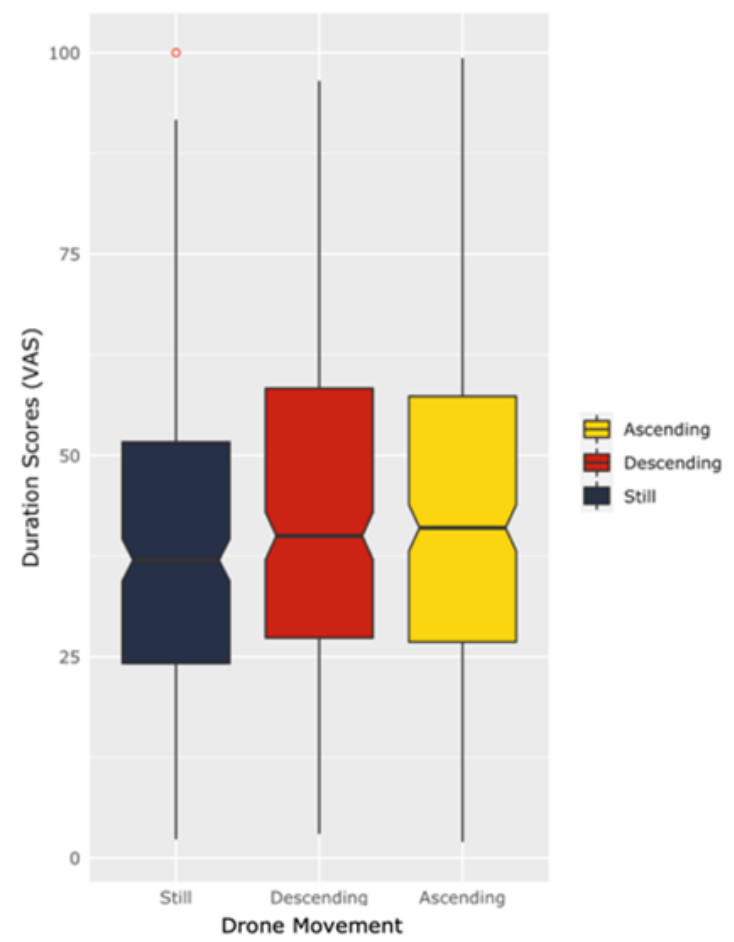

Fig. 4 | Duration. Boxplots depicting mean Visual Analogue Scale (VAS) ratings for dependent variable Duration with respect to main effect Drone Movement $(\mathrm{N}=31)$; see text for significant results.

\section{Liking}

The model explained $63.64 \%$ of the variance in Liking ratings, taking into account the random effects $\left(\mathrm{R}_{\mathrm{m}}{ }_{\mathrm{m}}=0.06, \mathrm{R}_{\mathrm{c}}{ }_{\mathrm{c}}=0.64\right)$. The model revealed a significant main effect of Drone Movement $\left(\chi^{2}(2)=28.68, p<.0001\right)$, showing that participants Liked Ascending more than Descending $\left(t_{(780)}=2.70, \mathrm{SE}=1.11, p=.020\right.$; Ascending: $\mathrm{M}=36.6, \mathrm{SE}=3.08$; Descending: $\mathrm{M}=33.6, \mathrm{SE}=3.08)$, Ascending more than Still $\left(t_{(780)}=5.36, \mathrm{SE}=1.11, p<.0001 ; \mathrm{Still}: \mathrm{M}=\right.$ 30.6, $\mathrm{SE}=3.08)$, and Descending more than Still $\left(t_{(780)}=2.70, \mathrm{SE}=1.11, p=.022\right)$, see Figure 5A. A significant main effect for Actor Presence was found $\left(\chi^{2}(2)=71.27, p<.0001\right)$, showing that participants Liked Female more than Male $\left(t_{(780)}=3.57, \mathrm{SE}=1.11, p=.001\right.$; Female: $\mathrm{M}=$ 38.1, $\mathrm{SE}=3.08$; Male: $\mathrm{M}=34.1, \mathrm{SE}=3.08)$, Female more than None $\left(t_{(780)}=8.41, \mathrm{SE}=1.11\right.$, $p<.0001$; None: $\mathrm{M}=28.7, \mathrm{SE}=3.08)$, and Male more than None $\left(t_{(780)}=4.84, \mathrm{SE}=1.11, p\right.$ $<.0001)$, see Figure 5B. A significant main effect for Image Speed was found $\chi^{2}(2)=14.31, \mathrm{p}$ $<.001)$, showing that participants liked Normal more than Slow $\left(t_{(780)}=3.17, \mathrm{SE}=1.11, p=\right.$ 
.005 ; Normal: $\mathrm{M}=36.0, \mathrm{SE}=3.08$; Slow: $\mathrm{M}=32.5, \mathrm{SE}=3.08$ ), and Normal more than Very Slow $\left(t_{(780)}=3.37, \mathrm{SE}=1.11, p=.002\right.$; Very Slow: $\left.\mathrm{M}=32.3, \mathrm{SE}=3.08\right)$, see Figure $5 \mathrm{C}$.

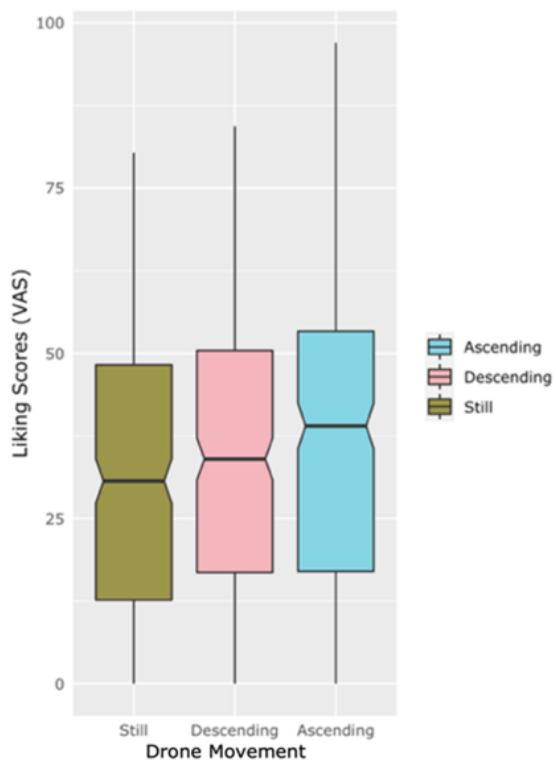

A

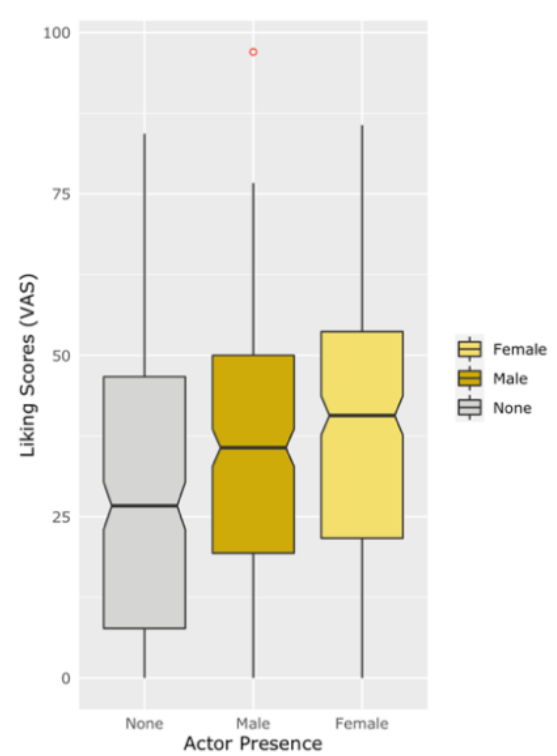

B

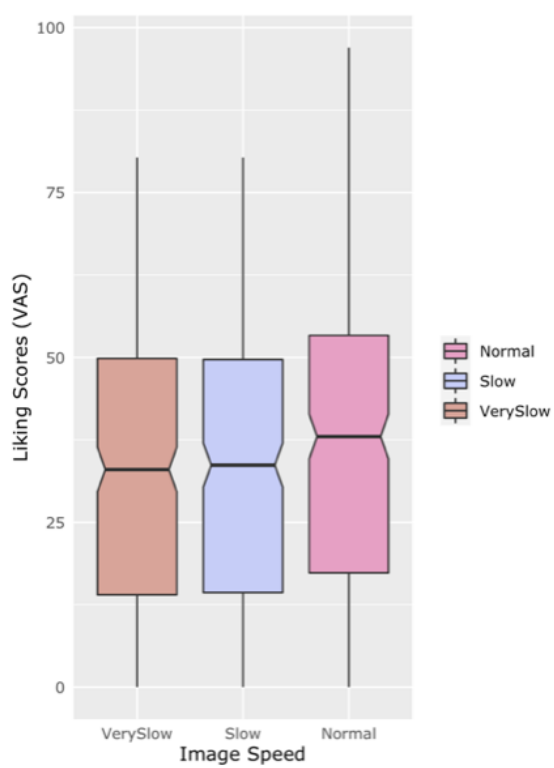

C

Fig. 5A - C |Liking. Boxplots depicting mean Visual Analogue Scale (VAS) ratings for dependent variable Liking with respect to main effect Drone Movement (5A), Actor Presence (5B) and Image Speed (5C) (N=31); see text for significant results.

\section{Movement}

The model explained $72.93 \%$ of the variance in Movement ratings, taking into account the random effects $\left(R_{m}^{2}=0.40, R_{c}^{2}=0.73\right)$. The model revealed a significant main effect of Drone Movement $\left(\chi^{2}(2)=1097.27, p<.0001\right)$, showing that participants perceived more Movement in 
Ascending than in Descending $\left(t_{(780)}=3.58, \mathrm{SE}=1.22, p=.001\right.$; Ascending: $\mathrm{M}=63.5, \mathrm{SE}=$ 3; Descending: $\mathrm{M}=59.1, \mathrm{SE}=3)$, Ascending more than Still $(t(780)=30.31, \mathrm{SE}=1.22, p<$ $.0001 ;$ Still: $\mathrm{M}=26.4, \mathrm{SE}=3)$, and Descending more than Still $\left(t_{(780)}=26.73, \mathrm{SE}=1.22, p<\right.$ .0001), see Figure 6A. A significant main effect for Actor Presence was found $\left(\chi^{2}(2)=45.14, p\right.$ $<.0001)$, showing that participants perceived more Movement in Female than in None $\left(t_{(780)}=\right.$ 5.93, $\mathrm{SE}=1.22, p<.0001$; Female: $\mathrm{M}=52.2, \mathrm{SE}=3$; None: $\mathrm{M}=44.9, \mathrm{SE}=3$ ), and in Male with respect to None $\left(t_{(780)}=5.71, \mathrm{SE}=1.22, p<.0001\right.$; Male: $\left.\mathrm{M}=51.9, \mathrm{SE}=3\right)$, see Figure 6B. A significant main effect for Image Speed was found $\left.\chi^{2}(2)=59.19, p<.0001\right)$, showing that participants perceived more Movement in Normal than in Slow $\left(t_{(780)}=4.66, \mathrm{SE}=1.22, p<\right.$ .0001 ; Normal: $\mathrm{M}=54.7, \mathrm{SE}=3$; Slow: $\mathrm{M}=49.0, \mathrm{SE}=3$ ), in Normal more than Very Slow $\left(t_{(780)}=7.63, \mathrm{SE}=1.22, p<.0001 ;\right.$ Very Slow: $\left.\mathrm{M}=45.4, \mathrm{SE}=3\right)$, and in Slow more than Very Slow $(z=2.98, \mathrm{SE}=1.22, p=.009)$, see Figure $6 \mathrm{C}$.

The model also showed a significant Drone Movement*Actor Presence interaction $\left(\chi^{2}(4)=\right.$ 11.25, $p=.024)$, showing that participants perceived more Movement in Ascending Female than in Ascending None $\left(t_{(780)}=5.27, \mathrm{SE}=2.12, p<.0001\right.$; Ascending Female: $\mathrm{M}=67.2$, SE =3.24; Ascending None: $\mathrm{M}=56.0, \mathrm{SE}=3.24$ ), more Movement in Ascending Male than in Ascending None $\left(t_{(780)}=5.30, \mathrm{SE}=2.12, p<.0001\right.$; Ascending Male: $\left.\mathrm{M}=67.3, \mathrm{SE}=3.24\right)$, more Movement in Descending Male than in Descending None $\left(t_{(780)}=3.62, \mathrm{SE}=2.12, p=\right.$ .009; Descending Male: $\mathrm{M}=61.8, \mathrm{SE}=3.24$; Descending None: $\mathrm{M}=54.1, \mathrm{SE}=3.24$ ), more Movement in Ascending Female than in Still Female $\left(t_{(780)}=18.53, \mathrm{SE}=2.12, p<.0001\right.$; Ascending Female: $\mathrm{M}=67.2, \mathrm{SE}=3.24$; Still Female: $\mathrm{M}=27.9, \mathrm{SE}=3.24$ ), more Movement in Descending Female than in Still Female $\left(t_{(780)}=15.81, \mathrm{SE}=2.12, p<.0001\right.$; Descending Female: $\mathrm{M}=61.4, \mathrm{SE}=3.24)$, more Movement in Ascending Male than in Still Male $\left(t_{(780)}=\right.$ 19.16, $\mathrm{SE}=2.12, p<.0001$; Ascending Male: $\mathrm{M}=67.3, \mathrm{SE}=3.24$; Still Male: $\mathrm{M}=26.7$, $\mathrm{SE}$ =3.24), more Movement in Descending Male than in Still Male $\left(t_{(780)}=16.58, \mathrm{SE}=2.12, p<\right.$ 0001; Descending Male: $\mathrm{M}=61.8, \mathrm{SE}=3.24$ ), more Movement in Ascending None than in Still None $\left(t_{(780)}=14.81, \mathrm{SE}=2.12, p<.0001\right.$; Ascending None: $\mathrm{M}=56.0, \mathrm{SE}=3.24$; Still None: $\mathrm{M}=24.7, \mathrm{SE}=3.24)$, and more Movement in Descending None than in Still None $\left(t_{(780)}\right.$ $=13.91, \mathrm{SE}=2.12, p<.0001$; Descending None: $\mathrm{M}=54.1, \mathrm{SE}=3.24)$. 


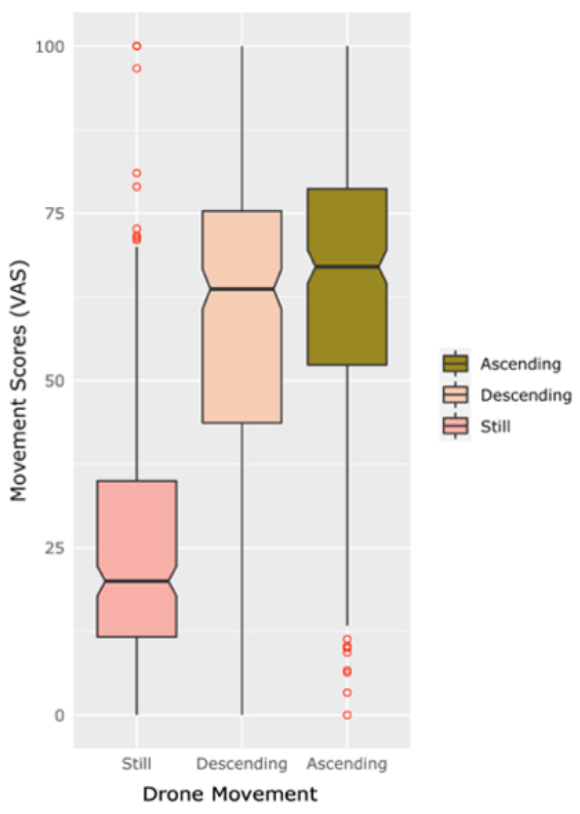

A

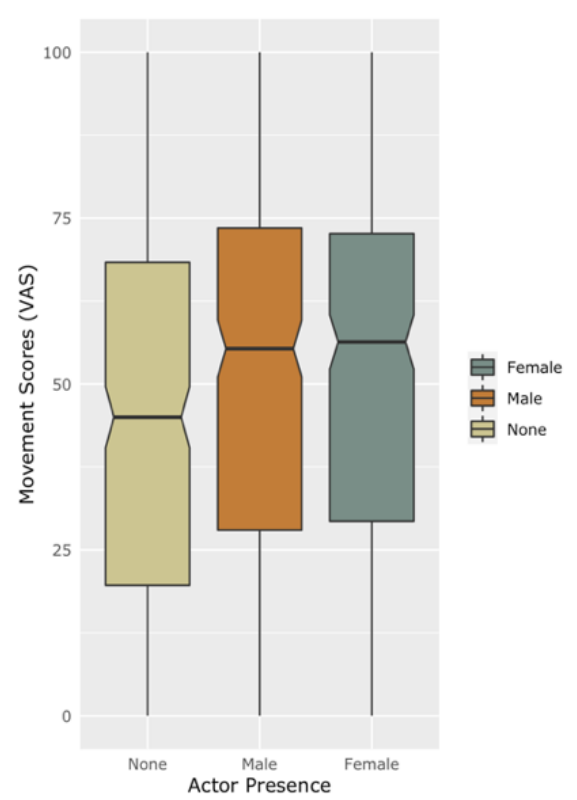

B

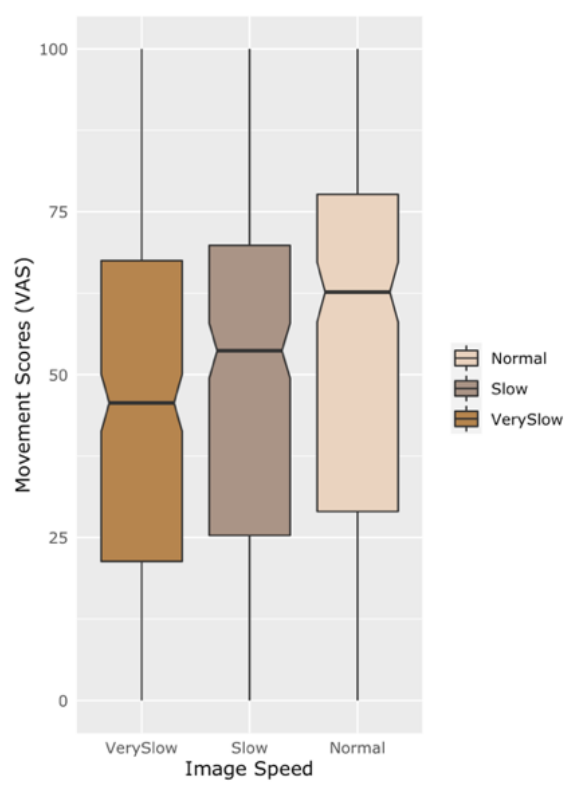

C

Fig. 6A - C | Movement. Boxplots depicting mean Visual Analogue Scale (VAS) ratings for dependent variable Movement with respect to main effects Drone Movement (6A), Actor Presence (6B) and Image Speed (6C) $(\mathrm{N}=31)$; see text for significant results.

\section{Physical Involvement}

The model explained $66.53 \%$ of the variance in Physical Involvement ratings, taking into account the random effects $\left(\mathrm{R}_{\mathrm{m}}^{2}=0.12, \mathrm{R}_{\mathrm{c}}{ }_{\mathrm{c}}=0.67\right)$. The model revealed a significant main effect of Drone Movement $\left(\chi^{2}(2)=175.86, p<.0001\right)$, showing that participants felt more 
Physically Involved with Ascending than with Still $\left(t_{(780)}=12.14, \mathrm{SE}=1.26, p<.0001\right.$; Ascending: $\mathrm{M}=40.6, \mathrm{SE}=3.53$; Still: $\mathrm{M}=25.3, \mathrm{SE}=3.53$ ), and Descending more than Still $\left(t_{(780)}=10.69, \mathrm{SE}=1.26, p<.0001\right.$; Descending: $\left.\mathrm{M}=38.8, \mathrm{SE}=3.53\right)$, see Figure 7A. A significant main effect for Actor Presence was found $\left(\chi^{2}(2)=52.03, p<.0001\right)$, showing that participants felt more Physically Involved with Female with respect to None $\left(t_{(780)}=5.79, \mathrm{SE}\right.$ $=1.26, p<.0001$; Female: $\mathrm{M}=37.0, \mathrm{SE}=3.53$; None: $\mathrm{M}=29.7, \mathrm{SE}=3.53$ ), and more with Male with respect to None $\left(t_{(780)}=6.62, \mathrm{SE}=1.26, p<.0001\right.$; Female: $\left.\mathrm{M}=38.0, \mathrm{SE}=3.53\right)$, see Figure 7B. A significant main effect for Image Speed was found $\chi^{2}(2)=39.58, p<.0001$ ), showing that participants felt more Physically Involved with Normal than with Slow $\left(t_{(780)}=\right.$ 4.19, $\mathrm{SE}=1.26, p<.0001$; Normal: $\mathrm{M}=39.3, \mathrm{SE}=3.53$; Slow: $\mathrm{M}=34.0, \mathrm{SE}=3.53$ ), and with Normal more than with Very Slow $\left(t_{(780)}=6.16, \mathrm{SE}=1.26, p<.0001\right.$; Very Slow: $\mathrm{M}=$ 31.5, $\mathrm{SE}=3.52$ ), see Figure 7C.

The model also showed a significant Drone Movement*Actor Presence interaction $\left(\chi^{2}(4)=\right.$ 14.96, $p=.005)$, showing that participants felt more Physically Involved with Ascending Female than with Ascending None $\left(t_{(780)}=5.55, \mathrm{SE}=2.18, p<.0001\right.$; Ascending Female: $\mathrm{M}$ $=44.2, \mathrm{SE}=3.75$; Ascending None: $\mathrm{M}=32.1, \mathrm{SE}=3.75$ ), more Physically Involved with Ascending Male than with Ascending None $\left(t_{(780)}=6.24, \mathrm{SE}=2.18, p<.0001\right.$; Ascending Male: $\mathrm{M}=45.7, \mathrm{SE}=3.75$ ), more Physically Involved with Descending Male than with Descending None $\left(t_{(780)}=4.06, \mathrm{SE}=2.18, p=.002\right.$; Descending Male: $\mathrm{M}=42.6, \mathrm{SE}=3.75$; Descending None: $\mathrm{M}=33.8, \mathrm{SE}=3.75$ ), more Physically Involved with Ascending Female than with Still Female $\left(t_{(780)}=7.91, \mathrm{SE}=2.18, p<.0001\right.$; Still Female: $\left.\mathrm{M}=26.9, \mathrm{SE}=3.75\right)$, more Physically Involved with Descending Female than with Still Female $\left(t_{(780)}=5.98, \mathrm{SE}=\right.$ 2.18, $p<.0001$; Descending Female: $\mathrm{M}=39.9, \mathrm{SE}=3.75)$, more Physically Involved with Ascending Male than with Still Male $\left(t_{(780)}=9.09, \mathrm{SE}=2.18, p<.0001\right.$; Still Male: $\mathrm{M}=25.8$, $\mathrm{SE}=3.75)$, more Physically Involved with Descending Male than with Still Male $\left(t_{(780)}=7.71\right.$, $\mathrm{SE}=2.18, p<.0001$; Descending Male: $\mathrm{M}=42.6, \mathrm{SE}=3.75)$, more Physically Involved with Ascending None than with Still None $\left(t_{(780)}=4.03, \mathrm{SE}=2.18, p=.002\right.$; Still None: $\mathrm{M}=23.3$, $\mathrm{SE}=3.75)$, and more Physically Involved with Descending None than with Still None $\left(t_{(780)}=\right.$ $4.82, \mathrm{SE}=2.18, p<.0001)$. 


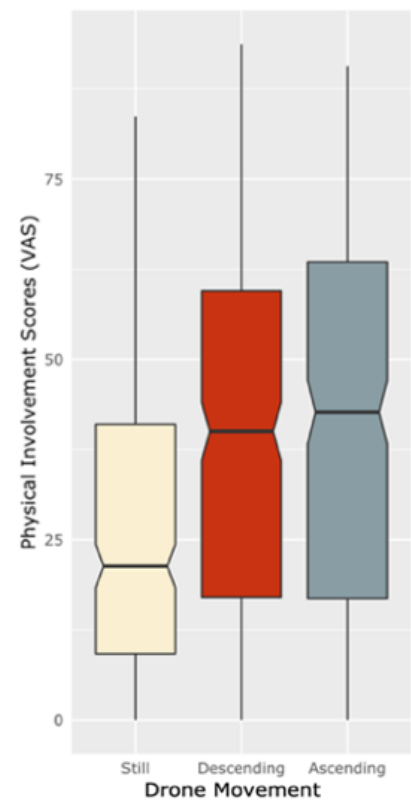

A
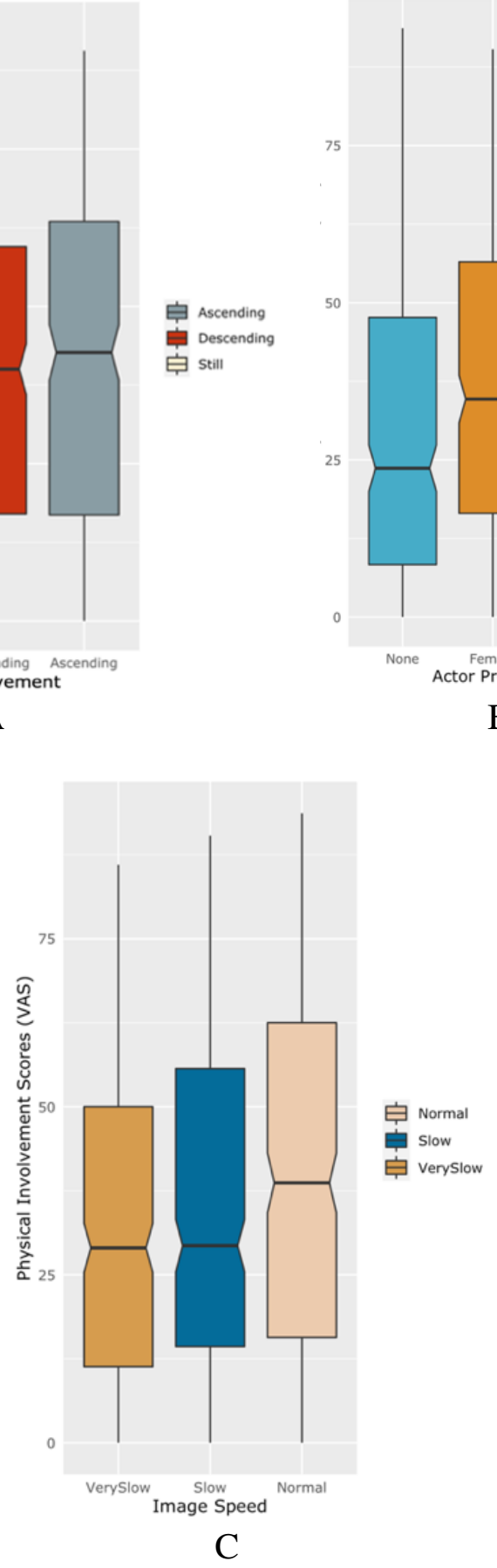

Fig. 7A - C | Physical Involvement. Boxplots depicting mean Visual Analogue Scale (VAS) ratings for dependent variable Physical Involvement with respect to main effects Drone Movement (7A), Actor Presence (7B) and Image Speed (7C), see text for significant results.

\section{Emotional Involvement}

The model explained $63.44 \%$ of the variance in Emotional Involvement ratings, taking into account the random effects $\left(\mathrm{R}^{2} \mathrm{~m}=0.075, \mathrm{R}^{2} \mathrm{c}=0.63\right)$. The model revealed a significant main 
effect of Drone Movement $\left(\chi^{2}(2)=13.74, p<.001\right)$, showing that participants found Ascending to be more Emotionally Involving than Descending $\left(t_{(780)}=3.48, \mathrm{SE}=1.26, p=.002\right.$; Ascending: $\mathrm{M}=37.6, \mathrm{SE}=3.43$; Descending: $\mathrm{M}=33.2, \mathrm{SE}=3.43$ ), and Ascending more than Still $\left(t_{(780)}=2.85, \mathrm{SE}=1.26, p=.013 ;\right.$ Still: $\left.\mathrm{M}=34.0, \mathrm{SE}=3.43\right)$, see Fig. 8A. A significant main effect for Actor Presence was found $\left(\chi^{2}(2)=138.52, p<.0001\right)$, showing that participants found Female to be more Emotionally Involving than None $\left(t_{(780)}=10.99, \mathrm{SE}=1.26, p<.0001\right.$; Female: $\mathrm{M}=40.3, \mathrm{SE}=3.43$; None: $\mathrm{M}=26.5, \mathrm{SE}=3.43$ ), and Male more Emotionally Involving than None $\left(t_{(780)}=9.15, \mathrm{SE}=1.26 ;, p<.0001\right.$; None: $\left.\mathrm{M}=38.0, \mathrm{SE}=3.43\right)$, see Fig. 8B. A significant main effect for Image Speed was found $\left(\chi^{2}(2)=6.44, p=0.04\right)$, showing that participants felt more Emotionally Involved with Normal than with Slow $\left(t_{(780)}=2.12, \mathrm{SE}=\right.$ 1.26, $p=.09$; Normal: $\mathrm{M}=39.3, \mathrm{SE}=3.43$; Slow: $\mathrm{M}=34.0, \mathrm{SE}=3.43$ ), and with Normal more than with Very Slow $\left(t_{(780}=2.27, \mathrm{SE}=1.26, p=.061\right.$; Very Slow: $\left.\mathrm{M}=33.9, \mathrm{SE}=3.53\right)$, see Fig. 8C. 


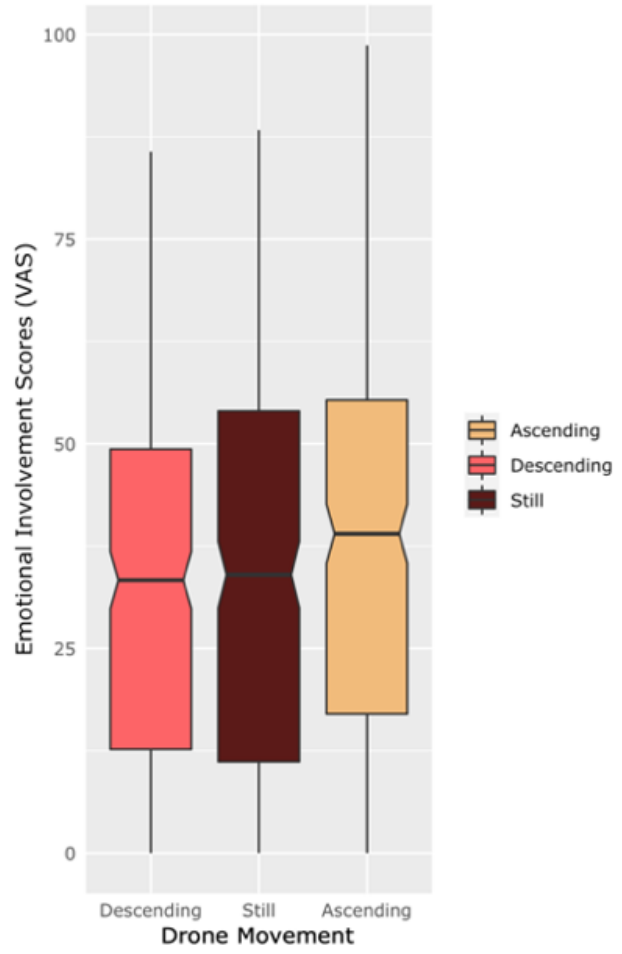

A

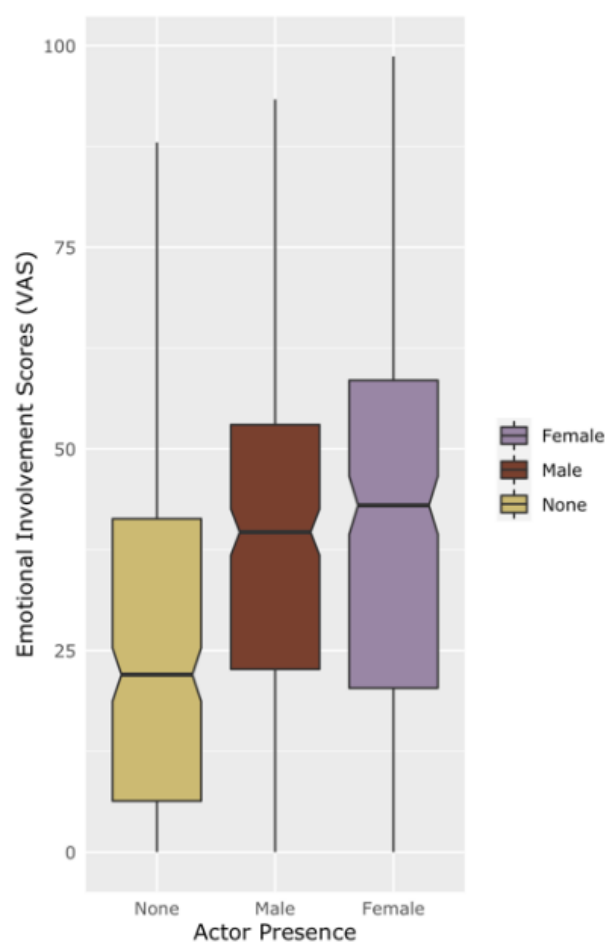

B

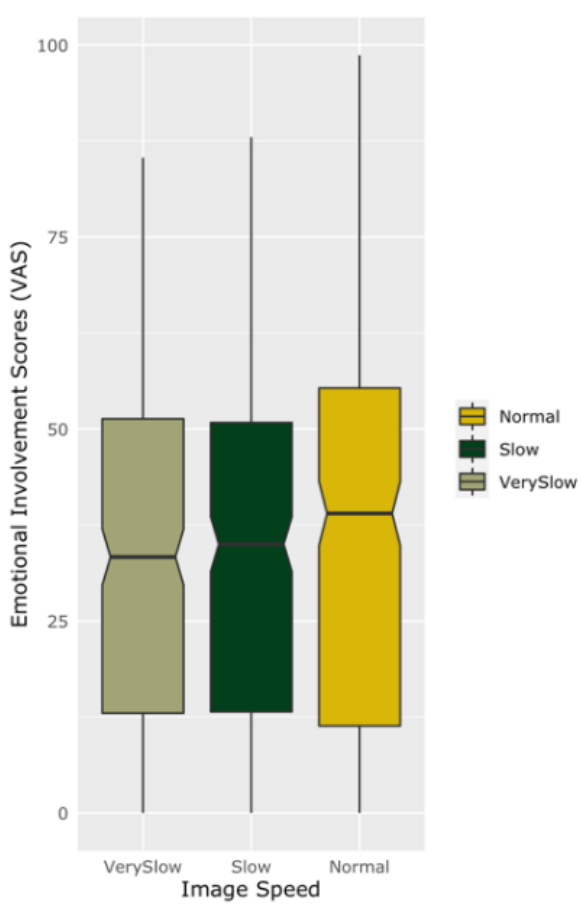

$\mathrm{C}$

Fig. 8A - C | Emotional Involvement. Boxplots depicting mean Visual Analogue Scale (VAS) ratings for dependent variable Emotional Involvement with respect to main effects Drone Movement (8A), Actor Presence (8B) and Image Speed (8C) $(\mathrm{N}=31)$; see text for significant results. 


\section{Discussion}

Previous studies have demonstrated that the observation of camera movement (Heimann et al., 2014, 2019) and human bodily gestures in videos (Gastaut and Bert 1954; Buccino et al. 2001; Aziz-Zadeh et al. 2006; Calvo-Merino et al. 2005, 2006; Orgs et al. 2008; Aglioti et al. 2008; Streltsova et al. 2010; Abreu et al. 2012) evoke sensorimotor resonance in the viewer. In the present study, we investigated the impact of Drone Movement, Actor Presence and Image Speed on participants' ratings of perceived Duration, perceived Movement, Liking, Physical Involvement and Emotional Involvement. In order to increase the ecological validity of the study, we collaborated with professional filmmaker and drone pilot to create 81 novel and carefully controlled video stimuli modeled after the staircase scene in The Cranes Are Flying (1957). This scene was chosen in particular due to its expression of cinematic affect through the motif of "rising" in the embodied aesthetics of the actor and the camera. Its use as a template for stimuli creation enabled the manipulation and control for multiples variables of interest.

Firstly, for the dependent variable Duration, results demonstrate a significant main effect for Drone Movement. Ascending and Descending conditions were perceived to have a longer Duration with respect to Still (even though all stimuli have a duration of 10 seconds), supporting a study by Brown (1995) which demonstrates that stimulus motion lengthens perceived time. Contrary to our hypothesis, no significant differences were found between conditions for perceived Duration for the main effect Image Speed. Rather than a distortion in the perception of subjective time in slow motion conditions, participants perceived stimuli durations in terms of their actual running time.

For the dependent variable Liking, results demonstrate that there are significant main effects for Drone Movement, Actor Presence and Image Speed. It was shown that Ascending received significantly higher ratings for Liking than Descending and Still, and Descending more than Still. It was also shown that Female received significantly higher ratings for Liking with respect to Male, which suggests that Female conditions are found to be more pleasing in terms of appearance or movement fluidity, and Female and Male have significantly higher ratings with respect to None, suggesting that the appeal of the stimuli is enhanced with an actor, whose presence attributes meaning to the context of the video (i.e., a staircase). 
Results for the Movement measure suggest that there are significant main effects for Drone Movement, Actor Presence and Image Speed. It was demonstrated that, in line with our hypothesis, Ascending and Descending received significantly higher ratings for Movement with respect to Still and, notably, that Ascending was perceived to evoke more Movement than Descending. These results are in line with prior neuroimaging studies on sensorimotor engagement during the observation of human and camera movement (Buccino et al., 2001; Aziz-Zadeh et al. 2006; Calvo-Merino et al. 2005, 2006; Orgs et al. 2008; Aglioti et al. 2008; Abreu et al. 2012), and provide further evidence in support of embodied simulation theory. Furthermore, a distinction has been demonstrated in the perception of Ascending with respect to Descending, suggesting that Ascending movement, embodied in the act of running up the stairs against the force of gravity, requires greater effort (i.e., exertion), and this greater exertion modulates the perception of movement in participants. Neuroimaging studies are needed in order to investigate differences in sensorimotor engagement between Ascending and Descending drone/actor movement. It was also found that Female and Male Actor Presence were rated as evoking significantly more Movement with respect to None (with no significant difference between Female and Male), which is in line with the "doubly" embodied nature of Female and Male conditions: whereas No Actor conditions have one vector of movement, i.e., the drone, Actor conditions have two, i.e., the drone and the human body. Results also show that Normal conditions were perceived as evoking more Movement than Slow and Very Slow, and Slow more than Very Slow, indicating greater perceived embodiment for "ecological" movement (i.e., original image speed) than for "slow motion" movement. Participants rated Movement precisely in terms of visualized apparent motion in a given time frame, rather than in terms of perceived effort.

For Physical Involvement, results demonstrate significant main effects for Drone Movement, Actor Presence and Image Speed. Like for the Movement measure, it was found that Ascending and Descending were perceived as evoking more Physical Involvement than Still. It was also found that None clips were rated as significantly less Physically Involving than Female and Male ones, again supporting embodied simulation theory, which suggests that we resonate more with conspecifics and familiar motor repertoires. Although the absence of others in the video image may increase the impression of "immersion" in the scene and, as a result, identification with the drone and simulation of its rotatory trajectory in space, participants found actor presence to be more involving on a motor level. In fact, results from the Drone 
Movement*Actor Presence interaction effect demonstrate that even in the absence of an actor, participants felt more Physically Involved when the drone was moving (i.e., Ascending/Descending), echoing the Steadicam results of Heimann et al. (2019) showing that camera movement alone evokes sensorimotor engagement in viewers.

Finally, for Emotional Involvement, results demonstrated significant main effects for Drone Movement, Actor Presence and Image Speed. Participants rated Ascending as more Emotionally Involving than Still and, notably, Ascending as more Emotionally Involving than Descending. This result indicates that the stronger affect evoked by Ascending movement may be driven by greater perceived exertion and thus stronger sensorimotor engagement. Both Ascending and Descending clips portray goal-oriented movements - going up and going down toward something, but "ascent" feels more affecting than "descent". Another possible explanation may be that Ascending drone/actor movement is perceived in terms of the motif of "rising"/ "upness", and the embodied meaning of this gesture is felt to be more emotionally involving with respect to "staying/ "standing" or "downward"/ "falling". Future studies may help elucidate how Ascending and Descending actor/drone movements are perceived in terms of valence, i.e., whether a more "positive" valence is attributed to Ascent and a more "negative" valence is attributed to Descent. Regardless of that, the greater Emotional Involvement of Ascending movement validates the artistic decision of Kalatozov (the director of the original film) in associating the joy of the protagonist to the motif of physical rising epitomized by the staircase, as well as a confirmation of the emotional metaphor of joy/rising more generally. It was also found that Female and Male are more Emotionally Involving than None, suggesting again that the presence of an actor provides meaning to the scene and facilitates emotional identification in viewers. Finally, our results showed that Normal Image Speed is more Emotionally Involving than Slow or Very Slow, seemingly contradicting the ubiquitous praxis of using slow motion in order to dramatize a film scene. However, a study by Wöllner and colleagues (2018) demonstrates that music was found to enhance the impact of stretched time, significantly augmenting physiological activation and perceived arousal and valence, suggesting that the emotional intensity of slow-motion scenes may be driven predominantly by the film score. Indeed, the results for Image Speed across Liking, Movement, and Physical Involvement falsify our initial hypothesis that slowing down the film image, and thus rendering motion more salient, would increase perceived motion, appeal and involvement measures. The 
present results, instead, demonstrate preference for and greater involvement with ecological movement.

Altogether, these results provide strong empirical evidence for the theory of embodied simulation (Gallese 2005; Gallese et al. 2004; Gallese and Sinigaglia 2011; Gallese 2014) and engagement with the actor and camera bodies during audiovisual experience (Heimann et al. 2014, 2019; Gallese and Guerra 2012, 2020), in particular. Future studies are needed to further investigate the impact of drone movement with or without human bodily movement on cortical sensorimotor activation in the brain. 


\section{References}

Abreu, Ana Maria, Macaluso, Emiliano, Azevedo, Ruben T., Cesari, Paola, Urgesi, Cosimo and Salvatore Maria Aglioti. 2012. 'Action Anticipation beyond the Action Observation Network: A Functional Magnetic Resonance Imaging Study in Expert Basketball Players'. European Journal of Neuroscience 35 (10): 1646-54.

Aglioti, Salvatore M, Cesari, Paola, Romani, Michela and Cosimo Urgesi. 2008. 'Action Anticipation and Motor Resonance in Elite Basketball Players'. NATURE NEUROSCIENCE 11 (9): 8.

Agostinho, Daniela, Maurer, Kathrin and Kristin Veel. 2020. 'Introduction to The Sensorial Experience of the Drone, The Senses and Society,' 15:3, 251-258, DOI: $10.1080 / 17458927.2020 .1820195$

Aziz-Zadeh, Lisa, Wilson, Stephen M., Rizzolatti, Giacomo and Marco Iacoboni. 2006. 'Congruent Embodied Representations for Visually Presented Actions and Linguistic Phrases Describing Actions'. Current Biology 16 (18): 1818-23. https://doi.org/10.1016/j.cub.2006.07.060.

Babiloni, Claudio, Babiloni, Fabio, Filippo Carducci, Cincotti, Febo, Cocozza, Guido, Del Percio, Claudio, Moretti, Davide V. and Paolo Maria Rossini. 2002. 'Human Cortical Electroencephalography (EEG) Rhythms during the Observation of Simple Aimless Movements: A High-Resolution EEG Study'. NeuroImage 17 (2): 559-72. https://doi.org/10.1006/nimg.2002.1192.

Bates, Douglas, Mächler, Martin, Bolker, Ben and Steve Walker. 2015. 'Fitting Linear Mixed-Effects Models Using Lme4'. ArXiv Preprint ArXiv:1406.5823.

Brown, Scott W. 1995. 'Time, Change, and Motion: The Effects of Stimulus Movement on Temporal Perception'. Perception \& Psychophysics 57: 105-16.

Buccino, Giovanni, Binkofski F., Fink, G. R., Fadiga, Luciano, Fogassi, Leonardo, Gallese, Vittorio, Seitz, R. J., Zilles, K., Rizzolatti, Giacomo and H.-J. Freund. 2001. 'Action Observation Activates Premotor and Parietal Areas in a Somatotopic Manner: An FMRI Study'. European Journal of Neuroscience 13 (2): 400-404. https://doi.org/10.1111/j.1460-9568.2001.01385.x.

Calvo-Merino, Beatriz, Glaser Daniel E., Grèzes, Julie, Passingham, Daniel E. and Patrick Haggard. 2005. 'Action Observation and Acquired Mot or Skills: An FMRI Study with Expert Dancers'. Cerebral Cortex 15 (8): 1243-49. https://doi.org/10.1093/cercor/bhi007.

Calvo-Merino, Beatriz, Grèzes, Julie, Glaser, Daniel E., Passingham, Richard E. and Haggard, Patrick. 2006. 'Seeing or Doing? Influence of Visual and Motor Familiarity in Action Observation'. Current Biology 16 (19): 1905-10. https://doi.org/10.1016/j.cub.2006.07.065.

Campbell, Robert. 2018. 'Drone Film Theory: The Immanentisation of Kinocentrism' Media Theory, Standard Issue, 2 (2), pp.52 - 78. hal-02047596. 
Carluccio, Giulia Anastasia and Federica Villa. 2006. Il Corpo Del Film. Scritture, Contesti, Stile, Emozioni. Carocci Editore.

Cherpillod, Alexandre, Mintchev, Stefano and Dario Floreano. 2019. 'Embodied Flight with a Drone', Third IEEE International Conference on Robotic Computing (IRC). DOI 10.1109/IRC.2019.00070.

Christensen, R. H. B. 2019. 'A Tutorial on fitting Cumulative Link Mixed Models with clmm2 from the ordinal Package', Tutorial for the R Package ordinal https://cran. $r$ project. org/web/packages/ordinal/Accessed, 1.

Christiansen, Steen Ledet. 2020. 'Unruly vision, synesthetic space: drone music videos', The Senses and Society, 15:3, 286-298, DOI: 10.1080/17458927.2020.1814565

Coëgnarts, Maarten, and Peter Kravanja, eds. 2015. Embodied Cognition and Cinema. Leuven: Leuven University Press.

Core, Team R. 2019. R: A Language and Environment for Statistical Computing. Vienna, Austria.

D’Aloia, Adriano and Ruggero Eugeni. 2014. 'Neurofilmology. An Introduction'. Cinema \& Cie. https://iris.unicampania.it/handle/11591/400317\#.X8fPEaozbOQ.

Davis, Mark H. 1980. 'A Multidimensional Approach to Individual Differences in Empathy'.

Di Pellegrino, Giuseppe, Fadiga, Luciano, Fogassi, Leonardo, Gallese, Vittorio and Giacomo Rizzolatti. 1992. 'Understanding Motor Events: A Neurophysiological Study | SpringerLink’. Experimental Brain Research, no. 91: 176-80.

Eriksson, Sara, Unander-Scharin, Åsa, Trichon, Vincent, Unander- Scharin, Carl, Kjellström, Hedvig and Kristina Höök. 2019. 'Dancing With Drones: Crafting Novel Artistic Expressions Through Intercorporeality'. In CHI Conference on Human Factors in Computing Systems Pro- ceedings (CHI 2019), May 4-9, 2019, Glasgow, Scotland UK, ACM, New York, NY, USA. https://doi.org/10.1145/3290605.3300847

Eugeni, Ruggero. 2018. Semiotica dei media. Le forme dell'esperienza. 6th ed. Roma: Carocci.

Fabrizio La Palombara. Available at: https://www.fabriziolapalombara.com (Accessed: 30 December 2020).

Faul, Franz, Erdfelder, Edgar, Lang, Albert-Georg and Axel Buchner. 2007. 'G* Power 3: A Flexible Statistical Power Analysis Program for the Social, Behavioral, and Biomedical Sciences'. Behavior Research Methods 39 (2): 175-91.

'Fly To Discover - Riprese Drone Cinematografiche Riprese Aeree Con Drone'. n.d. Accessed 15 December 2020. https://flytodiscover.it/. 
Fox, John. 2003. 'Effect Displays in R for Generalised Linear Models'. Journal of Statistical Software 8 (15): 1-27.

Frith, Uta and Chris Frith. 2010. 'The Social Brain: Allowing Humans to Boldly Go Where No Other Species Has Been'. Philosophical Transactions of the Royal Society B: Biological Sciences 365 (1537): 165-76. https://doi.org/10.1098/rstb.2009.0160.

Gallese, Vittorio. 2005. 'Embodied simulation: from neurons to phenomenal experience'. Phenomenology and the Cognitive Sciences 4: 23-48. https://doi.org/10.1007/s11097-0054737-z.

Gallese, Vittorio. 2009. 'Motor Abstraction: A Neuroscientific Account of How Action Goals and Intentions Are Mapped and Understood'. Psychological Research PRPF 73 (4): 48698. https://doi.org/10.1007/s00426-009-0232-4s.

Gallese, Vittorio. 2014. 'Bodily Selves in Relation: Embodied simulation as second-person perspective on intersubjectivity'. Philos Trans R Soc Lond B Biol Sci. 2014 Apr 28;369(1644):20130177. doi: 10.1098/rstb.2013.0177.

Gallese, Vittorio, Fadiga, Luciano, Fogassi, Leonardo and Giacomo Rizzolatti. 1996. 'Action Recognition in the Premotor Cortex'. Brain 119 (2): 593-609. https://doi.org/10.1093/brain/119.2.593.

Gallese, Vittorio and Michele Guerra. 2012. 'Embodying Movies: Embodied Simulation and Film Studies'. Cinema: Journal of Philosophy and the Moving Image 3: 183-210.

Gallese, Vittorio and Michele Guerra. 2014. 'The Feeling of Motion: Camera Movements and Motor Cognition'. Cinema \& Cie 14 (22-23): 103-12.

Gallese, Vittorio and Michele Guerra. 2020. The Empathic Screen: Cinema and Neuroscience. The Empathic Screen. Oxford University Press.

Gallese, Vittorio, Keysers, Christian and Giacomo Rizzolatti. 2004. 'A Unifying View of the Basis of Social Cognition'. Trends in Cognitive Sciences 8 (9): 396-403. https://doi.org/10.1016/j.tics.2004.07.002.

Gallese, Vittorio, and Corrado Sinigaglia. 2011. 'What Is so Special about Embodied Simulation?' Trends in Cognitive Sciences 15 (11): 512-19. https://doi.org/10.1016/j.tics.2011.09.003.

Gastaut, Henri J, and Jacques Bert. 1954. 'EEG Changes during Cinematographic Presentation (Moving Picture Activation of the EEG)'. Electroencephalography and Clinical Neurophysiology 6 (January): 433-44. https://doi.org/10.1016/00134694(54)90058-9.

Hari, Riitta, and Miiamaaria V. Kujala. 2009. 'Brain Basis of Human Social Interaction: From Concepts to Brain Imaging'. Physiological Reviews 89 (2): 453-79. https://doi.org/10.1152/physrev.00041.2007. 
Heimann, Katrin, Uithol, Sebo, Calbi, Marta, Umiltà, Maria Alessandra, Guerra, Michele, Fingerhut, Joerg and Vittorio Gallese. 2019. 'Embodying the Camera: An EEG Study on the Effect of Camera Movements on Film Spectators' Sensorimotor Cortex Activation'. Edited by Alessio Avenanti. PLOS ONE 14 (3): e0211026.

https://doi.org/10.1371/journal.pone.0211026.

Heimann, Katrin, Umiltà, Maria Alessandra, Guerra, Michele and Vittorio Gallese. 2014. 'Moving Mirrors: A High-Density EEG Study Investigating the Effect of Camera Movements on Motor Cortex Activation during Action Observation'. Journal of Cognitive Neuroscience 26 (9): 2087-2101. https://doi.org/10.1162/jocn_a_00602.

Jablonowski, M. 2020 Beyond drone vision: the embodied telepresence of first-person-view drone flight, The Senses and Society, 15:3, 344-358, DOI: 10.1080/17458927.2020.1814571

Kalatozov, M. 1957. Letiat Zhuravli [The Cranes Are Flying]. USSR: Mosfilm.

Kolesnikov, A. 2020a. The Cranes Are Flying (Kalatozov, 1957) - The Staircase Scene. Available at: https://www.youtube.com/watch?v=TRcZbexAoTU (Accessed: 3 December 2020).

Kolesnikov, A. 2020b. Stimulus 1. Available at: https://www.youtube.com/watch?v=PaUWr4Bw2jc (Accessed: 31 December 2020).

Kolesnikov, A. 2020c. Stimulus 2. Available at: https://www.youtube.com/watch?v=hIIjIXrClM (Accessed: 31 December 2020).

Kolesnikov, A. 2020d. Stimulus 3. Available at: https://www.youtube.com/watch?v=Tx7V0V_7zE (Accessed: 31 December 2020).

Kristensen, Simon Bang, Kristian Sandberg, and Bo Martin Bibby. 2020. 'Regression Methods for Metacognitive Sensitivity’. Journal of Mathematical Psychology 94: 102297.

Lenth, R., H. Singmann, J. Love, P. Buerkner, and M. Herve. 2020. Emmeans: Estimated Marginal Means, Aka Least-Squares Means (1.4. 5)[Computer Software].

McLuhan, Marshall. 2001. Understanding Media: The Extensions of Man. London: Routledge.

Muthukumaraswamy, Suresh D., Johnson, Blake W. and Nicolas A. McNair. 2004. 'Mu Rhythm Modulation during Observation of an Object-Directed Grasp'. Cognitive Brain Research 19 (2): 195-201. https://doi.org/10.1016/j.cogbrainres.2003.12.001.

Ndebele, Paul. 2013. 'The Declaration of Helsinki, 50 Years Later'. Jama 310 (20): 2145-46.

Oldfield, Richard C. 1971. 'The Assessment and Analysis of Handedness: The Edinburgh Inventory’. Neuropsychologia 9 (1): 97-113.

Orgs, Guido, Dombrowski, Jan-Henryk, Heil, Martin and Petra Jansen-Osmann. 2008. 'Expertise in Dance Modulates Alpha/Beta Event-Related Desynchronization during 
Action Observation'. European Journal of Neuroscience 27 (12): 3380-84. https://doi.org/10.1111/j.1460-9568.2008.06271.x.

Rizzolatti, Giacomo, Fadiga, Luciano, Gallese, Vittorio and Leonardo Fogassi. 1996.

'Premotor Cortex and the Recognition of Motor Actions'. Cognitive Brain Research, 13141.

Roberts, Ross, Callow, Nichola, Hardy, Lew, Markland, David and Joy Bringer. 2008.

'Movement Imagery Ability: Development and Assessment of a Revised Version of the Vividness of Movement Imagery Questionnaire'. Journal of Sport and Exercise Psychology 30 (2): 200-221.

Rogers, Sheena. 2013. In Psychocinematics: Exploring Cognition at the Movies, by Arthur P. Shimamura, Illustrated edition. Oxford, New York: Oxford University Press.

Sobchack, V. (2006) "“Cutting to the Quick": Techne, Physis, and Poiesis and the Attractions of Slow Motion', in Strauven, W. (ed.) The Cinema of Attractions Reloaded. Amsterdam University Press, pp. 337-352.

Sonkusare, Saurabh, Breakspear, Michael and Christine Guo. 2019. 'Naturalistic Stimuli in Neuroscience: Critically Acclaimed'. Trends in Cognitive Sciences 23 (8): 699-714. https://doi.org/10.1016/j.tics.2019.05.004.

Streltsova, Alena, Berchio, Cristina, Gallese, Vittorio and Maria Alessandra Umilta'. 2010. 'Time Course and Specificity of Sensory-Motor Alpha Modulation during the Observation of Hand Motor Acts and Gestures: A High Density EEG Study'. Exp Brain Res., 205(3):363-73. doi: 10.1007/s00221-010-2371-7.

Verhoeff, Nanna. 2012. Mobile Screens: The Visual Regime of Navigation, (Amsterdam: Amsterdam University Press.

Virilio, Paul. 1994. The Vision Machine, trans. Julie Rose, Bloomington: Indiana University Press.

Wickham, Hadley. 2016. Ggplot2: Elegant Graphics for Data Analysis. springer.

Witmer, Bob G., and Michael J. Singer. 1996. 'Measuring Presence in Virtual Environments: A Presence Questionnaire'. Presence 7 (3): 225-40. Revised by the UQO Cyberpsychology Lab (2004).

Wöllner, Clemens, Hammerschmidt, David and Albrecht, Henning. 2018. 'Slow Motion in Films and Video Clips: Music Influences Perceived Duration and Emotion, Autonomic Physiological Activation and Pupillary Responses'. PLOS ONE 13 (6): e0199161. https://doi.org/10.1371/journal.pone.0199161. 


\section{Conflicts of Interest}

The authors declare that the research was conducted in the absence of any commercial or financial relationships that could be construed as a potential conflict of interest.

\section{Author Contributions}

Conceived of the experiment: AK, MAU, MC; designed the experiment: AK, MAU, MC; performed the experiment: AK, MM; analyzed the data: AK, MC, MM, NL; wrote the initial draft: AK; initiated the project: AK, MC, MAU, VG, MG. All authors contributed substantially to the revision of the initial draft and approval of the final version of the manuscript.

\section{Funding}

For this research, AK received funding from the Cariparma Foundation.

\section{Acknowledgements}

The authors would like to thank Gioacchino Garofalo and Francesca Siri for their help with the research design and creation of the Python script, as well as Fabrizio La Palombara, Sandro Russello, Leyla Tesanoviç, Alessandro Benini and the lighting crew for their participation in the creation of the video clips.

*The actors gave their full consent for use of their image in publications. 